interventions as clinic users are younger, have higher rates of hazardous alcohol consumption and are potentially more resistant to standard brief interventions.

\section{P003 USING TRADITIONAL SEXUALITY DESCRIPTORS: ARE THEY USEFUL ANYMORE?}

${ }^{2}$ Katie Coates, ${ }^{1}$ Matthew Phillips*. 'Stockport NHS Foundation Trust, Stockport, UK; ${ }^{2}$ University of Manchester, Manchester, UK

\subsection{6/sextrans-2016-052718.58}

Introduction Sexuality is a complex topic in sociology and healthcare. It is multifactorial; combining gender, sex, sexual orientation and erotic desires. Three sexuality descriptors are commonly used: heterosexual, bisexual and homosexual. Women who have sex with women (WSW) and men who have sex with men (MSM) are classified as homosexual. These three descriptors are sometimes used in sexual health clinics in the UK as part of the coding to understand the demographics of service users.

Aims We wished to review if these descriptors matched patients' described behaviours in an integrated sexual health clinic.

Methods We reviewed 300 patients presenting to a UK sexual health clinic between April 2013 and September 2013. 100 patients were randomly chosen based on their sexuality descriptor, which had been self-selected when booking in. Electronic patient records were used to access patient histories. Stated sexuality and sexual behaviour were compared.

Results Out of the 300 patients selected, 88 were excluded, leaving 212 for analysis. $18.1 \%$ of patients described behaviour outside of the stated sexuality descriptor. $50.1 \%$ of the bisexual cohort, $1.8 \%$ of the heterosexual cohort and $3.5 \%$ of the homosexual cohort described behaviour different from the descriptor. Conclusion Our findings suggest that the current classifications of sexuality are inadequate to fully capture behaviours, although due to full sexual history taking clinical care is not compromised by this. Personal identity and choice of sexuality descriptors may bias epidemiological understanding of sexual behaviours if relying on these three traditional descriptors.

\section{P004 REGIONAL AUDIT OF THE MANAGEMENT OF SYPHILIS}

${ }^{1}$ Sumit Bhaduri*, ${ }^{2}$ Lisa Goodall, ${ }^{2}$ Kieran Fernando. ${ }^{1}$ Worcestershire Health and Care Trust, Worcestershire, UK; ${ }^{2}$ Staffordshire and Stoke on Trent Partnership NHS Trust, Stoke, UK

\subsection{6/sextrans-2016-052718.59}

Background/introduction BASHH guidelines for syphilis management were revised in 2015 and are awaiting publication.

Aim(s)/objectives To review regional clinics' syphilis management and adherence to provisional BASHH audit standards.

Methods Regional sexual health clinics were asked to review cases of syphilis diagnosed the previous year with respect to gender, sexuality, HIV status, pregnancy, screening for other sexually transmitted infections, disease stage, whether non treponemal titres were measured, follow up, treatments given, discussion of the Jarisch Herxheimer $(\mathrm{JH})$ reaction and partner notification (PN).

Results 13/15 (86\%) clinics participated. 161 case notes were reviewed. $81 \%$ were male, $54 \%$ were classified as men having sex with men. 34/161 (21\%) were HIV positive. 13/161 (19\%) were pregnant (in $84 \%$ written communication had been made to obstetric/neonatal teams). 138/161 (86\%) were screened for other STIs, 24\% cases having concomitant STIs. 63\% were early presentations. In $97 \%$ an RPR/VDRL was performed at commencement of therapy. 142/161 (88\%) were treated with parenteral penicillin. The $\mathrm{JH}$ reaction was discussed in $49 \%$ of early STS cases. In $75 \%$ a four-fold reduction of titres in RPRs was achieved. In $37 \%$ the patient attended for follow up for 12 months ( $16 \%$ had no follow up). In $86 \%$ of cases PN was performed with $87 / 161$ (54\%) of contacts being verified as having attended clinics for screening and treatment.

Discussion/conclusion Areas for improvement regionally include discussion of $\mathrm{JH}$ reaction, demonstration of success of treatment, patient follow up and partner notification. A reaudit is planned in the future.

\section{P005 HEPATITIS C SCREENING BY COUNTRY OF BIRTH IN A GENITOURINARY MEDICINE CLINIC- HOW MUCH ARE WE MISSING?}

Jennifer Murira*, Eric Monteiro. Leeds Teaching Hospitals Trust, Leeds, UK

10.1136/sextrans-2016-052718.60

Background/introduction Screening for Hepatitis C at GUM clinics is recommended by NICE (PH43) in high risk populations. One of these risk groups are people born/brought up in a country with a prevalence $>2 \%$ of chronic hepatitis C.

Aim(s)/objectives To determine the rate of screening by country of birth in GUM clinic attendees before and after the introduction of a clinic specific guideline for Hep C screening.

Methods All GUM attendees who were seen between October 2013 and October 2014 and were born in a country of Hep C prevalence of $>2 \%$ were included. This data was linked to whether a hepatitis $\mathrm{C}$ serology test had been performed with the results server. The rate of screening before and after the introduction of guidelines in April 2014 was compared. All HIV positive individuals were excluded.

Results During the audit time frame, 2,664 patients were identified as being born in a country with high Hep $\mathrm{C}$ prevalence. 1299 attended in the 6 months pre guidelines, 1365 attended 6 months after. Introducing clinic guidelines led to a 2.88 times increase in screening (4.7\% vs $13.6 \%)$. During this period we diagnosed 3 cases of hepatitis $\mathrm{C}$ in people born in a high prevalence country.

Discussion/conclusion Introduction of guidelines improved screening in our clinic however the rate of screening remained low. Assuming 2\% prevalence we 'missed' 50 cases of Hep C. Major factors identified were clinician knowledge of the countries that should be screened and asking the patient their country of birth within the sexual history.

\section{P006 WORKING WITH MARGINALISED GROUPS: HOMELESS ADULTS AND STREET BASED COMMERCIAL SEX WORKERS}

Sian Warren*, Nicola Lomax. Dept Sexual Health, Cardiff Royal Infirmary, UK Cardiff,. 